\title{
IMPORTÂNCIA DO ÁCIDO LINOLEICO CONJUGADO (CLA) EM PRODUTOS DE ORIGEM ANIMAL
}

\author{
Renata Nayhara de Lima* \\ Jacinara Hody Gurgel Morais Leite** \\ José Geraldo Bezerra Galvão Junior**** \\ Andrezza Kyarelle Bezerra de Moura**** \\ Allison Ferreira de Lima****** \\ Patrícia de Oliveira Lima******
}

RESUMO: O termo CLA descreve um conjunto de isômeros geométricos do ácido linoleico com propriedades bioativas distintas, que têm duas duplas ligações separadas por apenas uma ligação simples. Assim, este trabalho trata-se de uma revisão bibliográfica baseada na literatura especializada, fundamentado através de consulta a artigos científicos selecionados em diferentes bases de dados com o objetivo de dar enfoque à importância do ácido linoleico conjugado (CLA) em produtos de origem animal e seus benefícios à saúde humana. Nesse contexto, em alimentos de origem animal é possível encontrar esse composto natural, principalmente na gordura do leite, carne e em alimentos naturalmente enriquecidos com este ácido e seus isômeros. O CLA tem propriedades bioativas distintas e é originário da biohidrogenação incompleta dos ácidos linoleico e linolênico realizada pelas bactérias ruminais ou da desaturação do trans-11 na glândula mamária e no intestino delgado. Os benefícios biológicos do CLA e dos isômeros cis-9 e trans-11, como um componente natural da gordura do leite, tem efeito anticarcinogênico, incluindo carcinomas na epiderme, tecido mamário e gastrintestinal. Dietas suplementadas com gorduras e a relação concentrado: volumoso, assim como a efetividade da fibra do volumoso podem aumentar a produção de leite, diminuir a produção de gordura e alterar seu perfil em ácidos graxos. Pesquisas avaliando os níveis de CLA nos produtos de origem animal e

Doutoranda do Programa de Pós-Graduação em Ciência Animal pela Universidade Federal Rural do Semi-Árido (UFERSA), Brasil.

** Doutoranda do Programa de Pós-Graduação em Ciência Animal pela Universidade Federal Rural do Semi-Árido (UFERSA), Brasil.

*** Doutorando do Programa de Pós-Graduação em Ciência Animal pela Universidade Federal Rural do Semi-Árido (UFERSA), Brasil.

**** Mestra em Ciência Animal pela Universidade Federal Rural do Semi-Árido (UFERSA), Brasil.

***** Mestrando do Programa de Pós-Graduação em Ciência Animal (PPGCA) pela Universidade Federal Rural do Semi-Árido (UFERSA), Brasil. E-mail: henresito@hotmail.com

****** Docente Adjunto IV do Departamento de Ciências Animais da Universidade Federal Rural do Semi-Árido (UFERSA), Brasil. 
o seu efeito benéfico sobre a saúde e qualidade de vida do homem têm apresentado resultados satisfatórios, embora muitas vezes controversos, sendo necessários novos estudos para comprovar os resultados e a segurança na utilização desse composto, para que possa se determinar a sua real eficácia.

PALAVRAS-CHAVE: Ácidos Graxos; Anticarcinogênico; Biohidrogenação; Síntese.

\section{THE IMPORTANCE OF CONJUGATED LINOLEIC ACID (CLA) IN ANIMAL-DERIVED PRODUCTS}

ABSTRACT: Conjugated Linoleic Acid (CLA) is a set of geometric isomers of linoleic acid with different bioactive properties, featuring two double links divided by a single link. Current analysis is a bibliographic review based on specialized literature selected at different databases to underscore CLA in animal-derived products and their advantages for human health. The natural compound may be found in animal-derived products, especially milk fat, beef and in food naturally enriched with the acid and its isomers. CLA has different bioactive properties and originates from incomplete bio-hydrogenation of linoleic and linolenic acid undertaken by rumen bacteria or by de-saturation of trans-11 in the mammary gland and in the small intestine. The biological benefits of CLA and its isomers cis-9 and trans-11, as a natural component of milk fat, have an anti-carcinogenic effect, including carcinomas in the epidermis, mammary and gastrointestinal tissue. Diets supplemented with fats, concentrate : roughage ratio and the effectiveness of the roughage fiber may increase milk production, decrease fat and change its profile in fatty acids. Research on CLA levels in animal-derived products and their beneficent effect on health and life quality have provided satisfactory results, albeit often controversial. Further studies are required to corroborate results and safety in the use of the compound so that its real efficacy may be thoroughly determined.

KEY WORDS: Fatty acids; Anticarcinogenic agents; Bio-hydrogenation; Synthesis.

\section{INTRODUÇÃO}

O aumento na eficiência da produção animal tem sido, e continua ser, uma importante consideração na produção de alimentos de origem animal. No entanto, há também o crescente reconhecimento de que tais produtos podem constituir-se 
em fatores contribuintes na prevenção e desenvolvimento de algumas enfermidades. Como resultado, tem-se dado ênfase ao desenvolvimento de produtos alimentares que apresentem concentração aumentada de componentes que possuam efeitos benéficos para a saúde humana. Santos et al. (2001) afirmam que a descoberta de novos componentes naturais em alimentos com diversas propriedades terapêuticas é atualmente um importante elemento na estratégia de prevenção e cura de doenças.

$\mathrm{O}$ ácido linoleico conjugado (CLA) refere-se a um grupo de ácidos graxos com 18 átomos de carbono, que foram descobertos por cientistas da Universidade de Wisconsin em Madison (USA) no final da década de 70. Consiste em um grupo de isômeros de posição e geométricos com duas duplas ligações conjugadas, ou seja, duplas que não são separadas por um grupo metileno, como no caso do ácido linoleico (LA), que é um dieno não conjugado presente nas gorduras de origem animal (FUNCK et al., 2007). Este tem sido alvo de diversas pesquisas no sentido de identificar os seus efeitos benéficos, dos quais já se observaram um conjunto de efeitos positivos, incluindo a redução da deposição de gordura corporal (GOUVÊA et al., 2012), alterações no metabolismo energético e na partição de nutrientes (PARK et al., 1997), efeitos antidiabéticos (BELURY et al., 2003), redução no desenvolvimento de aterosclerose (BOTELHO et al., 2007), melhoria na mineralização óssea (BOTELHO et al., 2005), modulação do sistema imune (HOUSEKNECHT et al., 1998) e efeito anticarcinogênico (DILZER; PARK, 2012; PIERRE et al., 2013; WANG et al., 2013; BAE et al., 2013).

Wood et al. (2003) relataram que o crescente interesse no desenvolvimento de estratégias de manipulação da composição de ácidos graxos da carne bovina está relacionado à necessidade de se produzir carne mais saudável para reduzir a associação do consumo de carne bovina à ocorrência dessas doenças. Santos et al. (2001) afirmam que a adição de ácidos graxos insaturados na dieta de vacas lactantes pode aumentar de forma natural o CLA e diminuir o teor de gordura no leite, melhorando assim a imagem dos produtos lácteos junto ao consumidor, uma vez que este está preferindo os alimentos que possuem menor teor de gordura e sem aditivos, como a adição de CLA de forma artificial.

Os teores de CLA nas gorduras de origem animal variam amplamente dentro de um rebanho, e estão relacionados a fatores associados à fermentação ruminal, 
relação concentrado: forragem, níveis de ingestão e o consumo de plantas ricas em ácido linoleico (MAIA et al., 2006). Isso sugere que a dieta exerce uma grande influência neste composto, e muitos fatores dietéticos são conhecidos como passíveis de afetar a concentração de CLA no leite, por exemplo. Assim, o conhecimento de estratégias alimentares para ruminantes que possam transformar os principais alimentos de origem animal em nutracêuticos, respondendo as atuais exigências de mercado com relação a alimentos saudáveis, tornam-se necessários. Com isso, o objetivo deste artigo de revisão foi relatar as diferentes estratégias alimentares para ruminantes exploradas no sentido de aumentar o CLA em produtos de origem animal, assim como relatar sua importância e impactos na saúde humana.

\section{CARACTERIZAÇÃo DA MOLÉCULA E BIOSSÍNTESE DE CLA}

O CLA corresponde a uma série de isômeros posicionais e geométricos do ácido octadecadienóico (ácido linoleico, 18:2 w-6), com duplas ligações conjugadas, ou seja, separadas somente por uma ligação simples carbono-carbono, em vez de existirem na configuração interrompida metilênica típicas. Essas configurações podem ser do tipo cis ou trans, e as duplas ligações estão presentes predominantemente nas posições 8 e 10, 9 e 11, 10 e 12 ou 11 e 13 (MOURÃO et al., 2005; BHATTACHARYA et al., 2006). O CLA aparece como componente minoritário da fração lipídica, principalmente encontrado na carne bovina, ovina, leite e derivados. A presença de ácidos graxos com duplas ligações conjugadas foi primeiramente demonstrada em produtos de origem animal por Booth et al. (1935) ao trabalhar com gordura do leite de vacas que pastavam no período de primavera.

$\mathrm{O}$ ácido linoleico conjugado encontrado na gordura do leite e da carne de ruminantes origina-se de duas formas. A primeira constitui-se no CLA formado durante a biohidrogenação ruminal do ácido linoleico; e a segunda é o CLA sintetizado pelo tecido animal a partir do trans-11 C18:1, um outro intermediário da biohidrogenação de ácidos graxos insaturados. Sabe-se que a maioria dos lipídeos das rações dos ruminantes é formada por ácidos graxos insaturados, os quais são quase em sua totalidade biohidrogenados pelas bactérias do rúmen. O processo de 
biohidrogenação é de suma importância, pois além de diminuir a concentração de lipídeos insaturados, os quais são tóxicos aos micro-organismos, contribui para a retirada de íons $\mathrm{H}+$ do ambiente ruminal, evitando seu acúmulo (PEREIRA et al., 2011). Este é antecedido pela lipólise, com a oxidação dos triacilgliceróis a ácidos graxos livres e glicerol, e a isomerização dos ácidos graxos insaturados, que consiste na mudança de orientação da dupla ligação da molécula do ácido graxo convertendo os isômeros nativos cis em isômeros trans, mudando a localização da dupla ligação na cadeia de carbono. A biohidrogenação é obtida através da adição de um íon hidrogênio no ponto de uma dupla ligação, resultando na conversão de ácidos graxos insaturados em seus saturados correspondentes. Portanto, a biohidrogenação de ácidos graxos poliinsaturados envolve passos sequenciais de isomerização e de hidrogenação (BESSA et al., 2000). Pereira et al. (2011) ressaltam que o processo de biohidrogenação ainda confere uma peculiaridade aos ruminantes, que é a composição da gordura corporal diferente da dietética, uma vez que a hidrogenação dos ácidos graxos insaturados tem como principal produto o ácido esteárico.

Uma vez que o processo de biohidrogenação não é 100\% completo para todos os poliinsaturados, algum ácido linoleico, linolênico e produtos intermediários tais como ácidos linoleico conjugados e trans-11 C18:1 (ácido trans vacênico) alcançam o duodeno e são absorvidos (HOLANDA et al., 2011). É razoável esperar que entre 60 e $85 \%$ das gorduras insaturadas sejam biohidrogenadas e certa proporção de ácidos graxos, 15 a 40\%, não flua para absorção no intestino delgado. Muitos desses ácidos estão normalmente na configuração trans, os quais são mais resistentes a biohidrogenação que as formas cis (STAPLES et al., 2001). Assim, o processo de biohidrogenação incompleto dos ácidos graxos insaturados permite a produção e absorção de intermediários deste processo. Griinari e Bauman (1999) ressaltam que, ironicamente, a biohidrogenação ruminal de lipídeos dietéticos é responsável pelos altos níveis de ácidos graxos saturados na gordura dos ruminantes, uma característica considerada indesejável em alguns aspectos da saúde humana.

Apenas uma pequena fração de CLA nos produtos obtidos a partir de ruminantes é proveniente diretamente do rúmen como intermediário da biohidrogenação. A maior proporção de CLA é efetivamente produzida no tecido animal, como por exemplo na glândula mamária, através da desaturação do ácido vacênico (C18: 
1 n11), reação bioquímica mediada pela enzima delta-9-desaturasa (VÁRADYOVÁ et al., 2008). Essa enzima age incluindo uma dupla ligação cis no carbono 9 , realizando um caminho inverso ao da biohidrogenação. $O$ ácido formado no processo é o ácido oleico, o que aumenta o conteúdo de ácidos graxos insaturados da gordura do leite, especialmente o ácido rumênico (cis-9, trans-11 C18:2).

Holanda et al. (2011), no entanto, afirmam que não está claro ainda se o aumento da concentração de CLA na gordura do leite resulta de um aumento da produção de CLA no rúmen ou se pela ação da enzima esteroil-CoA desaturase ( 9 desaturase) sobre o ácido vacênico (trans-11 C18:1) na glândula mamária.

\section{EFEITOS BENÉFICOS DO CLA NA SAÚDE HUMANA}

Embora o CLA seja associado a muitos potenciais efeitos benéficos, alguns estudos têm demonstrado a existência de efeitos colaterais tanto em estudos humanos como em modelos animais (MOURÃO et al., 2005). Estudos científicos realizados com seres humanos estabeleceram como seguro o consumo de $3 \mathrm{~g} / \mathrm{dia}$ de CLA para obter resultados benéficos em relação à saúde (STANTON et al., 1997). No que concerne ao tempo de consumo do CLA, essa é uma questão difícil de ser respondida, devido à escassez de estudos sobre o consumo durante longos períodos de tempo por seres humanos, uma vez que apenas estudos clínicos de curto prazo com pequeno número de indivíduos costumam ser realizados (GAULLIER et al., 2002; GAULLIER et al., 2004). Dessa maneira, algumas pesquisas têm sido realizadas a fim de estimar o consumo de CLA pela população: Ritzenthaler et al. (2001), acompanhando durante um ano as ingestões alimentares de um grupo composto por homens e mulheres, obtiveram valores de 212 e $151 \mathrm{mg} /$ dia de CLA total e 193 e $140 \mathrm{mg} /$ dia de cis-9, trans-11 para homens e mulheres, respectivamente. Fritsche; Steinhart (1998), utilizando-se de uma pesquisa de consumo nacional, estimaram um consumo de 430 e $350 \mathrm{mg}$ de cis-9, trans-11/dia para homens e mulheres, respectivamente, na Alemanha. Em uma pesquisa realizada com idosos suecos estimou-se que o consumo de CLA era de $160 \mathrm{mg} / \mathrm{dia}$ (JIANG et al., 1999). Estes resultados demonstram diferentes valores segundo o sexo, idade e país, no entanto, em todos 
eles verifica-se que o consumo de CLA está distante da ingestão recomendada pela pesquisa de Stanton et al. (1997), para que se observe efeito benéfico do CLA. Vale ressaltar que a maioria dos estudos que investigam os efeito benéficos foram realizados com a utilização de animais experimentais, enquanto que os estudos com humanos ainda são escassos e necessitam de maiores investigações.

Dentre estes efeitos, destaca-se a sua atividade antitumoral (BEDEL et al., 2017), já observada em diversos tecidos como o pulmão (ORALDI et al., 2013), estomacal (BAE et al., 2013), câncer de endométrio (WANG et al., 2013), colón (PIERRE et al., 2013), prostático (SONG et al., 2006), sendo que os tumores da glândula mamária parecem ser mais sensíveis a intervenção desse composto (MAJUMDER et al., 2002; KORONOWICZ et al., 2017). Estudos evidenciam que o CLA atua sobre o crescimento e desenvolvimento tumoral em seus diversos estágios (iniciação, promoção, progressão e metástase), por meio da diminuição ou retenção da multiplicação celular, atuando ainda no aumento da morte celular programada (apoptose) e, ainda, sobre a necrose (FIELD; SCHLEY, 2004).

Corroborando com o mencionado anteriormente, o ácido linoleico conjugado (CLA) demonstra exercer várias propriedades fisiológicas potenciais benéficas ao homem, incluindo atividades anti-carcinogênicas, anti-obesidade, anti-cardiovasculares e antidiabéticas (FUKE; NORNBERG, 2016; YANG et al., 2017).

$\mathrm{O}$ ácido linoleico conjugado tem se mostrado capaz de reduzir o risco das cardiopatias de forma indireta, por meio do controle dos fatores de risco associados, como diabetes mellitus tipo 2, dislipidemia e hipertensão, e também de forma direta, como por exemplo, por meio da redução de fatores pró-inflamatórios (BOTELHO, 2006). Ainda que não haja estudos suficientes que confirmem um possível efeito antiaterogênico do consumo de CLA em humanos, Mougios et al. (2001) mostraram que a suplementação com CLA $(0,7 \mathrm{~g} / \mathrm{dia})$ durante 4 semanas diminuiu os níveis séricos de colesterol total e triacilgliceróis. Da mesma maneira, alguns dados sugerem níveis plasmáticos significativamente mais baixos após a ingestão do isômero cis-9, trans-11 CLA, quando comparados ao grupo controle, em pacientes com histórico de doença aterosclerótica (STACHOWSKA et al., 2005).

Trabalhos com animais experimentais demonstraram que o CLA é capaz de reduzir a placa de ateroma. No estudo de Lee et al. (1994), realizado com coelhos 
mostrou que lesões arteriais induzidas experimentalmente foram inibidas após o consumo de CLA. Da mesma maneira, observou-se regressão das lesões ateroscleróticas pré-estabelecidas em coelhos que receberam de 0,5 a 1\% de CLA durante 90 dias (KRITCHEVSKY et al., 2004). Outros resultados importantes foram encontrados em estudos realizados com camundongos. Toomey et al. (2003) encontraram resultados positivos quando suplementaram camundongos knockout para apoE com 1\% de cis-9, trans-11 CLA. Estes animais, caracterizados por possuírem aterosclerose pré-estabelecida, apresentaram retardo no desenvolvimento de novas lesões, assim como regressão no tamanho das lesões já existentes. Alguns estudos com ratos também demonstraram resultados significativos com relação à alteração no perfil lipídico, e consequentemente na prevenção de doenças cardiovasculares (RAHMAN et al., 2001). Apesar desses bons resultados, algumas pesquisas têm demonstrado resultados contraditórios. Smedman; Vessby (2001) mostraram que a ingestão de 4,2 g de CLA/dia durante 12 semanas não afetou as concentrações de lipídeos séricos e lipoproteínas. Nenhum efeito sobre os teores de triacilgliceróis, colesterol total e HDL-colesterol séricos foi relatado por Petridou et al. (2003), quando estes estudaram o efeito da suplementação com 2,1 g de CLA/dia durante 45 dias em mulheres jovens sedentárias.

De maneira geral, os resultados que indicam efeito antiaterogênico do CLA estão relacionados à sua propriedade anti-inflamatória (ZULET et al., 2005). Algumas das possíveis teorias para explicar tal efeito sugerem que exista declínio da produção de colesterol, assim como de sua secreção pelo fígado (SAKONO et al., 1999), redução da síntese de triacilgliceróis, associada ao aumento de sua oxidação e maior ativação de proliferadores de peroxissoma gama (PPARg) (TOOMEY et al., 2003), inibição da produção de tromboxano e consequente diminuição da agregação plaquetária (STANGL, 2000), potencialização da ação da enzima oxidonítrico sintetase em nível endotelial, assim como atenuação da síntese de algumas prostaglandinas, como por exemplo, a prostaglandina I2.

Buscando avaliar o efeito do CLA sobre as funções celulares de macrófagos, Cook et al. (1993) isolaram macrófagos peritoniais de ratos alimentados com $0,5 \%$ de CLA. As células dos animais tratados apresentaram atividade fagocitária duas vezes maior quando comparado às células do grupo controle. Resultados similares 
foram observados por Yamasaki et al. (2000), suplementando ratos Sprague-Dawley com diferentes doses de CLA $(0 ; 0,05 ; 0,10 ; 0,25$ e $0,50 \%)$ durante 3 semanas, observou-se aumento na produção de $\operatorname{IgG}$ (imunoglobulina G), IgM (imunoglobulina M) e IgA (imunoglobulina A) pelo baço destes animais. Em humanos, a atividade do CLA mostrou-se diferente da encontrada em modelos experimentais. Dezessete mulheres saudáveis permaneceram confinadas em uma unidade metabólica durante 93 dias, recebendo nos primeiros 30 dias cápsulas de óleo de girassol (6 g/dia) para adaptarem-se. Ao final deste período, elas foram divididas em 2 grupos, sendo que 10 delas passaram a receber cápsulas com CLA (3,9 g/dia) e as demais continuaram a receber óleo de girassol. Após o experimento o estado imunológico destas mulheres foi comparado e verificou-se que não houve aumento no número de linfócitos T e B, granulócitos e monócitos em ambos os grupos (KELLY et al., 2000).

Numerosos estudos realizados com animais experimentais e também com humanos--vêm demonstrando a capacidade do CLA em reduzir a gordura corporal e aumentar a massa magra, seja por meio do consumo de alimentos enriquecidos ou da suplementação com este composto. Em geral, o CLA administrado nos grupos tratados (experimentais) está na forma de ácido graxo livre, encapsulado, em doses que variam entre 3 a $7,2 \mathrm{~g} /$ dia. Já para os grupos placebos (controle) são comumente utilizados óleo de oliva, girassol, soja ou ainda ácido oleico e/ou linoleico. Recentemente, alguns estudos observaram efeitos benéficos com a utilização do CLA após o consumo de alimentos enriquecidos com este ácido graxo, seja de forma intencional ou de maneira natural (DESROCHES et al., 2005). Em uma pesquisa realizada por Blankson et al. (2000), foram analisados 47 indivíduos obesos e com sobrepesos suplementados com 1,7;3,4; 5,1 ou 6,8 g/dia de CLA ou com $9 \mathrm{~g} /$ dia de óleo de oliva por 12 semanas. Após o tratamento, houve diminuição da gordura corporal não dependente da dose dos indivíduos pertencentes aos grupos suplementados com 3,4 e 6,8 g/dia de CLA. Contribuindo com estes resultados, Smedman; Vessby (2001) encontraram redução da gordura corporal de mulheres saudáveis suplementadas com 3,4 g/dia de uma mistura de CLA durante 12 semanas.

São vários os mecanismos propostos para explicar a alteração na composição corporal ocasionada pelo consumo de CLA, dentre eles estão: diminuição da proliferação e diferenciação de pré-adipócitos, diminuição da esterificação de ácidos 
graxos em triacilgliceróis, aumento do gasto energético, aumento da lipólise, alteração da atividade das enzimas envolvidas nos processos de oxidação e síntese de ácidos graxos, modificação da concentração de proteínas reguladoras do consumo alimentar e adipogênese, alteração da expressão de genes relacionados ao metabolismo lipídico, entre outros (WANG; JONES, 2004). Da mesma maneira, o CLA pode ser influenciado pelo tipo e quantidade de outros componentes da dieta, como proteínas (AKAHOSHI et al., 2004) e lipídeos (WANG; JONES, 2004). Estudos recentes revelaram que o CLA tem sua ação diminuída, como agente redutor da massa gorda, quando foram administradas dietas pobres em lipídeos (KIMBERLY et al., 2005).

Algumas evidências têm apontado que o ácido linoleico conjugado seria capaz de modular a mineralização óssea. Inúmeros estudos indicaram que o CLA altera a concentração de leptina, o que justificaria, de imediato, mudanças no metabolismo ósseo (CORINO et al., 2002; THOMAS; BURGUERA, 2002). Brownbill et al. (2005) realizaram estudo com 136 mulheres pós-menopausa, onde observou-se que a ingestão de CLA associada a suplementação de cálcio aumentou a massa óssea das mesmas, ressalta-se ainda que o principal isômero de CLA relacionado a este estudo foi o cis-9, trans-11, e não o trans-10, cis-12. Resultados favoráveis também foram observados por Banu et al. (2006) ao avaliar o efeito do CLA em indivíduos praticantes de atividade física. Ao avaliar a composição óssea em ratos ovarectomizados, Kelly; Cashman (2004) verificaram que o CLA pode diminuir a reabsorção óssea. Contudo, outros estudos não observaram diferença após a suplementação com CLA em marcadores para a saúde óssea e densidade mineral óssea (DOYLE et al., 2005; GAULLIER et al., 2004). Sendo assim, mais estudos de longa duração da interação entre cálcio e os isômeros do CLA tornam-se necessários para elucidar o efeito do CLA sobre a saúde óssea.

\section{CONCENTRAÇÃO DE CLA EM PRODUTOS DE ORIGEM ANIMAL}

O conteúdo de CLA nos alimentos varia em decorrência de numerosos fatores e difere de forma considerável de um alimento para outro. Dentre estes fatores, além da atividade enzimática e bacteriana, o teor de CLA varia também devido a 
fatores externos (ALONSO et al., 2003). O tipo de dieta oferecida ao ruminante não apenas é capaz de aumentar o teor de CLA nos alimentos, como alterar a proporção dos diferentes isômeros. Dessa maneira, buscando aumentar o teor de CLA nos alimentos por meio da manipulação dietética, diversos estudos têm sido realizados.

Apesar de a adição de óleo na dieta ter sido apontada como uma alternativa bastante eficiente para alterar o perfil lipídico da carne, considerando que a alimentação representa em torno de $60 \%$ dos custos totais da produção animal, o seu elevado custo pode, ainda, limitar a adoção desta tecnologia. Por outro lado, alguns resíduos agroindustriais, derivados da extração de óleo, representam um excelente recurso alimentar passível de aproveitamento na alimentação de ruminantes (OLIVEIRA, 2003). Dentre os diferentes resíduos disponíveis, os subprodutos derivados do algodão, girassol e canola têm despertado grande interesse, por apresentarem preço reduzido e elevada concentração de extrato etéreo.

\subsection{LEITE E DERIVADOS}

Diante do exposto anteriormente, espera-se que, quanto maior a concentração do 18:2n-6 (ácido linoleico) na dieta, maiores as chances de elevar a concentração de CLA na gordura do leite. Este comportamento foi evidenciado por Maia et al. (2006), ao testar diferentes óleos incorporados à ração de cabras em lactação. Os autores concluíram que o óleo de soja foi a fonte mais rica em ácido linoleico, seguido dos óleos de arroz e de canola. Os resultados demonstraram ainda que a inclusão de fontes de óleos vegetais à dieta aumentou a concentração de CLA na gordura do leite propiciando conteúdo de CLA 55\% superior em relação ao tratamento controle, com médias de 0,$91 ; 1,10 ; 1,43$ e 1,70\% para os tratamentos controle, óleo de canola, arroz e soja, respectivamente. O tratamento com óleo de soja mereceu maior destaque, pois, neste caso, a diferença na concentração de CLA em relação ao tratamento controle chegou a aproximadamente $87 \%$.

Mir et al. (2000) observaram aumento no teor de CLA no leite caprino com a suplementação com óleo de cártamo; nessa mesma espécie, Silva (2005) verificou aumentos nas proporções de ácidos graxos desejáveis no leite com a adição de óleo de soja, sabão de cálcio e grãos de soja na dieta; óleo de soja, arroz e canola também 
levaram ao aumento no ácidos graxos benéficos e CLA no leite caprino (BOUATTOUR et al., 2008).

De forma semelhante, Santos et al. (2001) observaram que a ração suplementada com óleo de soja aumentou significativamente o percentual de CLA, comparada à ração com grão de soja, que foi numericamente inferior à ração controle. Estes autores concluíram que isto ocorreu, provavelmente, devido ao fato de os ácidos linoleico e linolênico estarem mais disponíveis para ser biohidrogenados e, assim, formarem o CLA durante a fase de isomerização. Estes resultados, portanto, demonstram que a adição de óleo não protegido à dieta aumenta o teor de CLA, uma vez que o emprego deste tipo de suplemento propicia o ataque dos micro-organismos sobre estas fontes de energia de forma mais efetiva, favorecendo o processo de biohidrogenação, ao contrário do que ocorre com as sementes de oleaginosas, em que a fonte de lipídio está protegida por uma matriz protéica que impede a biohidrogenação, reduzindo a formação dos principais precursores do CLA (MAIA et al., 2006).

Luna et al. (2005) afirmam que a concentração total de CLA no leite ovino varia geralmente entre 0,6 e 1,0 g/100 g do total de ácidos graxos, com cerca de $80 \%$ representada pelo isômero C18:2 cis-9 trans-11. Essa concentração, contudo, pode ser elevada para valores próximos a 3,5 g/100 g, sobretudo pela inclusão de óleo na dieta dos animais.

Holanda et al. (2001) constataram que há uma correlação linear entre as concentrações de trans-10 C18:1 e trans-10, cis-12 CLA na gordura do leite e uma relação quadrática entre a redução na produção de gordura e o aumento do conteúdo de trans-10, cis-12 CLA na gordura do leite em vacas alimentadas com dietas com baixa relação volumoso: concentrado e suplementadas com óleo de girassol. Assim, o aumento de trans-10, cis-12 CLA no ambiente ruminal está associado com a depressão na gordura do leite, resultando no aumento deste isômero na gordura do leite. No trabalho de Oliveira et al. (2009), o teor de CLA (C18:2, cis 9, trans 11) no leite das búfalas foi influenciado pelas fontes de lipídeos nas dietas $(\mathrm{P}<0,05)$; no tratamento com óleo de soja, os teores de CLA praticamente dobraram. Estes valores estão na mesma faixa dos encontrados por Jiang et al. (1996), que relataram variação de 0,25 a $1,8 \%$ de CLA na gordura do leite de vacas. 
Van Nieuwenhove et al. (2004) observaram teor de 0,48\% de CLA no leite de búfalas, valor este bem abaixo das três dietas avaliadas neste estudo. Dhiman et al. (2000) verificaram aumento de $237 \%$ na produção de CLA em vacas em lactação que receberam $2 \%$ de óleo de soja na dieta. No Brasil, Eifert et al. (2006) observaram que a inclusão de óleo de soja na dieta de vacas proporcionou aumento de $230 \%$ no conteúdo de CLA. Dhiman et al. (1999) verificaram que o processamento do leite de búfalos em queijo não altera o teor de CLA, sugerindo que os queijos contendo altas concentrações de CLA só são produzidos a partir do leite que contenha também alto teor.

No trabalho de Pereira et al. (2011), que teve como objetivo avaliar o perfil de ácidos graxos do leite de vacas alimentadas com rações contendo níveis crescentes de torta de girassol, observou-se ausência de resposta estatística para CLA, diferentemente dos resultados obtidos por Kelsey et al. (2003), também com torta de girassol. É provável que a estas respostas sejam efeito do pequeno número da amostra de animais no trabalho de Pereira e colaboradores, já que Kelsey e colaboradores, com um número maior de animais, observaram variação de três vezes o conteúdo de CLA entre indivíduos e demonstraram que a base para a variação individual está mais relacionada à passagem pelo rúmen de CLA cis-9 trans-11 C18:2 e de trans-11 C18:1 e à atividade da 9-desaturase que a fase de lactação ou o grupo genético dos animais.

\subsection{CARNE}

Com o objetivo de avaliar a concentração do CLA na carne em diferentes sistemas de produção, Depetris; Santini (2005) concluíram que o sistema de produção e o plano nutricional oferecido aos animais modificam consideravelmente a composição química da carne e particularmente o perfil de ácidos graxos. Os sistemas de alimentação com alta participação de grãos na dieta (confinamento) resultaram em menor concentração de CLA, provavelmente devido à diminuição na biohidrogenação pelas bactérias do rúmen. Por outro lado, o sistema de alimentação baseado em forrageiras proporciona aumento de ácidos graxos poliinsaturados da dieta, associado a maior biohidrogenação ruminal, gerou elevadas concentrações de CLA na carne. 
No trabalho de Oliveira et al. (2008), que teve como objetivo avaliar os teores de ácido linoleico conjugado (CLA) e o perfil de ácidos graxos no músculo e na capa de gordura de novilhos bubalinos alimentados com diferentes fontes de lipídios, observou-se que o emprego do óleo de soja na dieta proporcionou maiores concentrações de CLA, além disso observou-se também menores concentrações de ácidos graxos saturados, principalmente os ácidos mirístico e palmítico, favorecendo a relação ácidos graxos insaturados (AGI)/ácidos graxos saturados (AGS).

Alguns fatores podem explicar o aumento nos teores de AGI com a administração de fontes lipídicas prontamente disponíveis para o animal, um deles seria a maior produção de propionato com o fornecimento de concentrado, o que aumenta a proporção de ácidos graxos insaturados nos depósitos corporais (LAWRENCE; FOWLER, 1997). Outra hipótese está relacionada com o pH ruminal, que, ao cair, diminui a lipólise e a biohidrogenação ruminal de ácidos graxos, ou que também pode elevar a deposição de AGI (SUKHIJA; PALMQUIST, 1990). Todavia, a hipótese mais aceita está relacionada com o efeito negativo dos AGI sobre as bactérias gram positivas, que são as principais responsáveis pelas reações de biohidrogenação (JENKINS; MCGUIRE, 2006).

Fernandes et al. (2009), avaliando uma dieta com cana-de-açúcar e grãos de girassol, verificou que esta proporcionou maiores teores de ácido linoleico e CLA muscular dos animais em relação à dieta convencional, com silagem de milho. Estes autores atribuíram tal fato à inclusão de grãos de girassol, que tem grande concentração de ácido linoleico, e à utilização da cana-de-açúcar como volumoso.

Santos-Silva et al. (2003), comparando dietas contendo grão de milho ou semente de girassol, observaram significante aumento na concentração de CLA de 4,1 para 7,0 mg/g de ácidos graxos totais, com o uso do grão oleaginoso. Ainda estes autores, estudando a inclusão de óleo de soja no concentrado e fornecendo feno de alfafa ad libitum para cordeiros, observaram significativo incremento na concentração de CLA no músculo Longissimus dos animais que receberam $8 \%$ de óleo de soja, em relação ao grupo controle (23,7 versus $5,5 \mathrm{mg} / \mathrm{g}$ de ácidos graxos totais). Arsenos et al. (2006) demonstraram, contudo, que o peso de abate pode afetar estas características, de forma que a alteração da dieta com intuito de elevar a concentração de CLA na carne pode ser ineficiente quando os animais são abatidos em pesos 
mais baixos, em função do reduzido período de tempo em que o animal permanece consumindo o alimento. Assim, considerando que o crescimento dos cordeiros no período pré-desmame é dependente, principalmente, da produção de leite da ovelha (PIRES et al., 2000), a manipulação da dieta destas, de forma a aumentar a excreção de CLA no leite, poderia favorecer a deposição de maior quantidade deste elemento na carne, o que poderia ser alcançado pela inclusão de óleo de soja na dieta das ovelhas (GOMEZ-CORTEZ et al., 2008). Esta prática, todavia, devido ao elevado preço do óleo vegetal, pode muitas vezes reduzir a lucratividade da atividade. Neste sentido, o uso de resíduos da agroindústria de extração de óleo pode caracterizar-se como uma alternativa promissora e altamente sustentável.

Diversas fontes lipídicas têm sido avaliadas para comprovar seu potencial em aumentar a quantidade de CLA em produtos de origem caprina e ovina; já o óleo de palmeira aumentou a proporção de ácidos graxos indesejáveis na gordura da carne ovina (CASTRO et al., 2005); Jeronimo et al. (2009) verificaram maior eficiência do óleo de girassol em relação ao de linhaça no aumento de CLA na carne de ovinos.

\section{CONSIDERAÇÕES FINAIS}

Vários trabalhos têm sido realizados para estudar a quantidade e o tipo de gordura a ser adicionada à dieta, sua aceitabilidade e digestibilidade com a finalidade de elevar os conteúdos de CLA em alimentos de origem animal, enquanto mantém a boa saúde animal e atende a demanda do mercado consumidor como alimento funcional. Pesquisas avaliando os níveis de CLA nos produtos de origem animal e o seu efeito benéfico sobre a saúde e qualidade de vida do homem têm apresentado resultados satisfatórios, embora muitas vezes controversos, sendo necessários novos estudos para comprovar os resultados e a segurança na utilização desse composto, para que possa se determinar a sua real eficácia. 


\section{REFERÊNCIAS}

AKAHOSHI, A. et al. Dietary protein modulates the effect of cla on lipid metabolism in rats. Lipids, Champaign, v. 39, p. 25-30, 2004.

ALONSO, L. et al. Production of free conjugated linoleic acid by lactobacillus acidophilus and lactobacillus casei of human intestinal origin. Journal of dairy science, Champaign, v. 86, n. 6, p. 1941-1946, 2003.

ARSENOS, G. et al. Fatty acid composition of lambs of indigenous dairy greek breeds of sheep as affected by post-weaning nutritional management and weight at slaughter. Meat science, v. 73, n. 1, p. 55-65, 2006.

BAE, C. et al. Xerocytosis is caused by mutations that alter the kinetics of the mechanosensitive channel. PNAS, v. 4, p. 1162-1168, 2013.

BANU, J. et al. Effects of conjugated linoleic acid and exercise on bone mass in young male balb/c mice. Lipids in health and disease, v. 5, n. 7, 2006.

BEDEL, H. A. et al. Hatice Asli Bedel, Nur Tukel Turgut, Aysegul Ugur Kurtoglu, Coskun Usta. Indian Journal Of Pharmaceutical Sciences, v. 79, n. 3, p. 328-334, 2017.

BELURY, M. et al. The conjugated linoleic acid (cla) isomer, t10c12-cla, is inversely associated with changes in body weight and serum leptin in subjects with type 2 diabetes mellitus. Journal of nutrition, v. 133, n. 1, p. 257-60, 2003.

BESSA, R. J. B. et al. Reticulo-rumen biohydrogenation and the enrichment of ruminant edible products with linoleic acid conjugated isomers. Livestock production science. v. 63, p. 201-211, 2000.

BLANKSON, H. et al. Conjugated linoleic acid reduces body fat mass in overweight and obese humans. Journal of nutrition, Philadelphia, v. 130, n. 12, p. 2943-2948, 2000.

BHATTACHARYA, A. et al. Biological effects of conjugated linoleic acid in health and disease. The journal of nutritional biochemistry, Stoneham, v. 17, p. 789-810, 2006. 
BOUATTOUR, M. A. et al. Feeding soybean oil to dairy goats increases conjugated linoleic acid in milk. Journal of dairy science, v. 91, p. 2399-2407, 2008.

BOOTH, R. G. et al. A study of seasonal variation in butter fat. Aseasonal spectroscopic variation in the fatty acid fraction. Biochemical Journal, v. 29, p. 133-137, 1935.

BOTELHO, A. P. et al. O efeito da suplementação com ácido linoléico conjugado sobre o perfil lipídico sérico em ratos. Revista Brasileira de Tecnologia Agroindustrial, v. 1, n. 2, 2007.

BOTELHO, A. P. et al. Correlação entre a gordura corporal e os teores séricos de leptina de ratos wistar suplementados com ácido linoléico conjugado. São Paulo, 2005. Anais do $8^{\circ}$ Congresso Nacional da Sociedade Brasileira de Alimentação e Nutrição. São Paulo, 172, 2005.

BOTELHO, A. P. et al. Ácido linoléico conjugado reduz a atividade da lípase lipoprotéica. In: CONGRESSO LATINOAMERICANO DE NUTRIÇÃO, 14., 2006. Anais... Florianópolis, 2006.

BROWNBILL, R. A. et al. Association between dietary conjugated linoleic acid and bone mineral density in postmenopausal women. Journal of the american college of nutrition, v. 24, p. 177-181, 2005.

CASTRO, T. et al. Fatty acid composition and carcass characteristics of growing lambs fed diets containing palm oil supplements. Meat science, 69: 757-764, 2005.

CHIN, S. F. et al. Conjugated linoleic acid (9,11-and 10, 12-octadecadienoic acid) is produced in conventional but not germ-free rats fed linoleic acid. Journal of Nutrition, v. 124: 694-701, 1993.

CORINO, C. et al. Influence of dietary linoleic acid in growth, meat quality, lipogenesis, plasma leptin and physiological variables of lipid metabolism in rabbits. Journal of animal science, Champaign, v. 80, n. 4, p. 1020-1028, 2002.

COOK, M. E. et al. Immune modulation by altered nutrient metabolism: nutritional control of immune-induced growth depression. Poultry science, Champaign, v. 72, n. 7, p. 301-1305, 1993.

DEPETRIS, G.; SANTINI, F. J. Sistemas de alimentación y su impacto sobre las carac- 
terísticas químicas y organolépticas de la carne en bovinos. Estación experimental agropecuaria balcare - grupo de nutrición, metabolismo y calidad de producto, 2005.

DESROCHES, S. et al. Lack effect of dietary conjugated linoleic acids naturally incorporated into butter on the lipid profile and body composition of overweight and obese men. American journal of clinical nutrition, New York, v. 82, p. 309-319, 2005.

DILZER, A.; PARK, Y. Implication of conjugated linoleic acid (cla) in human health. Critical reviews in food science and nutrition. v. 52, p. 488-513, 2012.

DOYLE, L. et al. Effect of dietary supplementation with conjugated linoleic acid on markers of calcium and bone metabolism in healthy adult men. European journal of clinical nutrition, v. 59, p. 432-440, 2005.

DHIMAN, T. R. et al. Conjugated linoleic acid content of milk from cows on conjugated linoleic acid and other fatty acids in milk from lactating dairy cows. Journal dairy science, v. 83, p. 2520-2528, 2000.

EIFERT, E. C. et al. Perfil de ácidos graxos e teor de ácido linoleico conjugado no leite de vacas alimentadas com dietas com diferentes fontes de carboidratos, com ou sem óleo de soja suplementado. Revista Brasileira de Zootecnia, v. 35, p. 1829$1837,2006$.

FERNANDES, A. R. M. et al. Composição química e perfil de ácidos graxos da carne de bovinos de diferentes condições sexuais recebendo silagem de milho e concentrado ou cana-de-açúcar e concentrado contendo grãos de girassol. Revista Brasileira de Zootecnia, v. 38, n. 4, p. 705-712, 2009.

FIELD, C. J.; SCHLEY, P. D. Evidence for potencial mechanisms for the effect of conjugated linoleic acid on tumor metabolism and immune function: lessons from n-3 fatty acids. American journal of clinical nutrition, New York, v. 79, p. 1190s-1198s, 2004.

FRITSCHE, J.; STEINHART, H. Amounts of conjugated linoleic acid (cla) in german foods and evaluation of daily intake. European food research and technology, Springer, v. 206, n. 2, p. 77-82, 1998.

FUKE, G.; NORNBERG, J. L. Systematic evaluation on the effectiveness of conjugated 
linoleic acid in human health. Critical Reviews In Food Science And Nutrition, v. 57, n. 1, p. 01-07, 2016.

FUNCK, L. G. et al. M. Ácido linoléico conjugado (cla) e sua relação com a doença cardiovascular e os fatores de risco associados. Archivos latinoamericanos de nutrición, Caracas, v. 56, n. 2, p. 123-134, 2007.

GAULLIER, J. M. et al. Clinical trial results support a preference for using CLA preparations enriched with two isomers rather than four isomers in human studies. Lipids, v. 37, n. 11, p. 1019-1025, 2002.

GAULLIER, J. M. et al. Conjugated linoleic acid supplementation for $1 \mathrm{y}$ reduces body fat mass in healthy overweight humans. The american journal of clinical nutrition, 79, 1118-1125, 2004.

GOMEZ-CORTES, P. et al. Milk production, conjugated linoleic acid content, and in vitro ruminal fermentation in response to high levels of soybean oil in dairy ewe diet. Journal of dairy science, v. 91, n. 4, p. 1560-1569, 2008.

GOUVÊA, M. M. et al. Ácidos Linoleicos Conjugados (ALC) - Os Benefícios que Exercem sobre a Saúde Humana e as Principais Metodologias Analíticas Aplicadas para a sua Determinação em Leites. Revista Virtual de Química, v. 4, n. 6, p. 653-669, 2012.

GRIINARI, J. M.; BAUMAN, D. E. Biosynthesis of conjugated linoleic acid and its incorporation into meat and milk in ruminants. Advances in conjugated linoleic acid research, v. 1, p. 180-200, 1999.

HOLANDA, M. A. C. et al. Suplementação dietética de lipídios na concentração de ácido linoléico conjugado na gordura do leite. Acta veterinaria brasilica, v. 5, n. 3, p. 221-229, 2011.

HOUSEKNECHT, K. L. et al. Dietary conjugated linoleic acid normalizes impaired glucose tolerance in the zucker diabetic fatty fa/fa rat. Biochem biophys res commun., v. 244, n. 3, p. 911-7, 1998.

JENKINS, T. C. Lipid metabolism in the rumen. Journal dairy science, v. 76, p. 3851-3863, 1993. 
JENKINS, T. C.; MCGUIRE, M. A. Major advances in nutrition: impact on milk composition. Journal dairy science, v. 89, p. 1302-1310, 2006.

JERÓNIMO, E. et al. Effect of dietary replacement of sunflower oil with linseed oil on intramuscular fatty acids of lamb meat. Meat science, 83: 499-505, 2009.

JIANG, J. et al. Relation between the intake of milk fat and the occurrence of conjugated linoleic acid in human adipose tissue. The american journal of clinical nutrition, New York, v. 70, n. 1, p. 21-27, 1999.

JIANG, J. et al. Occurrence of conjugated cis-9 trans-11 octadecadienoic acid in bovine milk: effects of feed and dietary. Journal dairy science, v. 79, p. 438-445, 1996.

KELLY, O.; CASHMAN, K. D. The effect of conjugated linoleic acid on calcium absorption and bone metabolism and composition in adult ovarectomised rats. Prostaglandins, leukotrienes, and essential fatty acids, Amsterdam, v. 71, n. 5, p. 295-301, 2004.

KELLY, D. S. et al. Dietary conjugated linoleic acid did not alter immune status in young healthy women. Lipids, Champaign, v. 35, n. 10, p. 1065-1071, 2000.

KELLY, G. S. Conjugated linoleic acid (CLA): a review. Alternative Medicine Review, v. 6, n. 4, p. 367-367, 2001.

KELSEY, J. A. et al. The effect of breed, parity, and stage of lactation on conjugated linoleic acid (cla) in milk fat from dairy cows. Journal of dairy science, v. 86, n. 8, p. 2588-2597, 2003.

KIMBERLY, M. et al. Dietary coconut oil increases conjugated linoleic acid-induced body fat loss in mice independent of essencial fatty acid deficiency. Biochimica et biophysica acta, Amsterdam, v. 1737, p. 52-60, 2005.

KORONOWICZ, A. A. et al. Fatty Acids of CLA-Enriched Egg Yolks Can Induce Transcriptional Activation of Peroxisome Proliferator-Activated Receptors in MCF-7 Breast Cancer Cells. Ppar Research, v. 2017, p. 1-12, 2017.

KRAMER, J. K. G. et al. Rumenic acid: A proposed common name for the major conjugated linoleic acid isomer found in natural products. Lipids, v. 33, n. 8, p. 835-835, 1998. 
KREIDER, R. B. et al. Effects of conjugated linoleic acid supplementation during resistance training on body composition, bone density, strength, and selected hematological markers. Journal of strength and conditioning research, v. 16, p. 325-334, 2002.

KRITCHEVSKY, D. et al. Conjugated linoleic acid isomer effects in atherosclerosis: growth and regression of lesions. Lipids, Champaign, v. 39, n. 7, p. 611-616, 2004.

LAWRENCE, T. L. J.; FOWLER, V. R. Growth of farm animals. London: Cambridge University, 1997.

LEE, K. N. et al. Conjugated linoleic acid and atherosclerosis in rabbits.

Atherosclerosis, Limerick, v. 108, n. 1-2, p. 19-25, 1994.

LUNA, P. et al. Conjugated linoleic acid in ewe milk fat. Journal of dairy research. v. 72, n. 4, p. 415-424, 2005.

MAJUMDER, B. et al. Conjugated linoleic acids (clas) regulate the expression of key apoptotic genes in human breast cancer cells. The faseb journal, Bethesda, v. 16, p. 1447-1449, 2002.

MAIA, F. J. et al. Inclusão de fontes de óleo na dieta de cabras em lactação: produção, composição e perfil dos ácidos graxos do leite. Revista Brasileira de Zootecnia, v. 35, n. 4, p. 1504-1513, 2006.

MARTÍNEZ, M. A. L. Influencia de la nutrición sobre el contenido y tipo de ácidos grasos en la carne de los rumiantes. Archivos de Zootecnia, v. 56, p. 45-66, 2007.

MEINERT, T. L. et al. Efficacy and safety of dietary supplements containing cla for the treatment of obesity: evidence from animal and human studies. Journal of lipid research, Bethesda, v. 44, p. 216-221, 2003.

MIR, Z. L. J. et al. Fatty acid composition and conjugated linoleic acid content of intramuscular fat in crossbred cattle with and without wagyu genetics fed a barley-based diet. Canadian Journal of Animal Science, v. 80, n. 1, 195-197, 2000.

MOUGIOS, V. Effect of supplementation with conjugated linoleic acid in human serum lipids and body fat. The journal of nutrition biochemistry, Stoneham, v. 
12, n. 10, p. 585-594, 2001.

MOURÃO, D. M. et al. Ácido linoléico conjugado e perda de peso. Revista de nutrição, Campinas, v. 18, n. 3, p. 391-399, 2005.

OLIVEIRA, R. L. et al. Composição química e perfil de ácidos graxos do leite e muçarela de búfalas alimentadas com diferentes fontes de lipídeos. Arquivo Brasileiro de Medicina Veterinária e Zootecnia, v. 61, n. 3, p. 736-744, 2009.

OLIVEIRA, R. L. et al. Ácido linoleico conjugado e perfil de ácidos graxos no músculo e na capa de gordura de novilhos bubalinos alimentados com diferentes fontes de lipídios. Arquivo Brasileiro de Medicina Veterinária e Zootecnia, v. 60, n. 1, p. 169-178, 2008.

OLIVEIRA, E. R. Aproveitamento de resíduos agroindustriais na alimentação de ovinos. In: SIMPÓSIO INTERNACIONAL SOBRE CAPRINOS E OVINOS DE CORTE, 2. , 2003, João Pessoa. Anais... João Pessoa: Sincorte, 2003. 672p.

ORALDI, M. et al. Cla reduces inflammatory mediators from a 427 human lung cancer cells and a427 conditioned medium promotes differentiation of c2c12 murine muscle cells. Lipids, v. 48, p. 29-38, 2013.

PARODI, P. W. Conjugated octadecadienoic acids of milk fat. Journal of dairy science, Champaign, v. 60, n. 5, p. 1550-1553, 1977.

PARK, Y. et al. Effect of conjugated linoleic acid on body composition in mice. Lipids. v. 32, n. 8, p. 853-858, 1997.

PEREIRA, E. S. et al. Torta de girassol em rações de vacas em lactação: produção microbiana, produção, composição e perfil de ácidos graxos do leite. Acta scientiarum Animal science, Maringá, v. 33, n. 4, p. 287-394, 2011.

PIRES, C. C. et al. Cria e terminação de cordeiros confinados. Ciência rural, Santa Maria, v. 30, n. 5, p. 875-880, set./out. 2000.

PIERRE, A. S. et al. Trans-10, cis-12 conjugated linoleic acid induced cell death in human colon cancer cells through reactive oxygen species-mediated ER stress. Biochimica et biophysica acta, v. 183, n. 4, p. 759-768, 2013. 
PETRIDOU, A. et al. Supplementation with cla: isomer incorporation into serum and effect on body fat of women. Lipids, Champaign, v. 38, n. 8, p. 805-811, 2003.

RAHMAN, S. M. et al. Effects of conjugated linoleic acid on serum leptin concentration, body-fat accumulation, and b-oxidation of fatty acid in oletf rats. Nutrition, New York, v. 17, n. 5, p. 385-390, 2001.

RITZENTHALER, K. L. et al. Estimation of conjugated linoleic acid intake by written dietary assessment methodologies underestimates actual intake evaluated by food duplicate methodology. Journal of nutrition, Philadelphia, v. 131, n. 5, p. 15481554, 2001.

SANTOS, F. L. et al. Anticarcinogenic properties of conjugated linoleic acid. Nutrir e: rev. Soc. Bras. Alim. Nutr . = j. Brazilian soc. Food nutr., São Paulo, v. 22, p. $121-132$, dez., 2001b.

SANTOS, F. L. et al. Efeito da suplementação de lipídios na ração sobre a produção de ácido linoleico conjugado (cla) e a composição da gordura do leite de vacas. Revista Brasileira de Zootecnia, v. 30, n. 6, p. 1931-1938, 2001.

SANTOS-SILVA, J. et al. The effect of supplementation with expanded sunflower seed on carcass and meat quality of lambs raised on pasture. Meat science, v. 65, p. 13011308, 2003.

SAKONO, M. et al. Dietary conjugated linoleic acid reciprocally modifies ketogenesis and lipid secretion by rat liver. Lipids, Champaign, v. 34, n. 9, p. 997-1000, 1999.

SHANTHA, N. C. et al. Evaluation of conjugated linoleic acid concentrations in cooked beef. Journal of Agricultural and Food Chemistry, v. 42, n. 8, p. 1757-1760, 1994.

SILVA, M. M. C. 2005. Suplementação de lipídios em dietas para cabras leiteiras. Viçosa: Universidade Federal de Viçosa, 129p. Tese, Universidade Federal de Viçosa, 2005.

SMEDMAN, A.; VESSBY, B. Conjugated linoleic acid supplementation in humans -metabolic effects. Lipids, Champaign, v. 36, n. 8, p. 773-781, 2001.

STANGL, G. I. Conjugated linoleic acids exhibit a strong fat-to-lean partitioning effect 
reduce serum vldl lipids and redistribute tissue lipids in food-restricted rats. The journal of nutrition, Philadelphia, v. 130, n. 5, p. 1140-1146, 2000.

STACHOWSKA, E. et al. Is conjugated linoleic acid a protective factor in atherosclerosis? Study with the use of neural networks. Annual academy of medicine, v. 51, n. 2, p. 27-32, 2005.

STAPLES, C. Fatty supplementation strategies for lactating dairy cows diets. In: SIMPÓSIO INTERNACIONAL EM BOVINOS DE LEITE: NOVOS CONCEITOS EM NUTRIÇÃO, 2, 2003, Lavras. Anais... Lavras: UFLA - FAEPE, 2001. 161-178.

STANTON, C. et al. Conjugated linoleic acid (cla) - a health-promoting component of dairy fats. Farm \& food, Dublin, v. 7, n. 2, p. 19-20, 1997.

SONG, H. J. et al. Induction of apoptosis and inhibition of nf-kappab activation in human prostate cancer cells by the cis- 9 , trans- 11 but not the trans-10, cis-12 isomers of conjugated linoleic acid. The prostate, New York, v. 66, p. 839-846, 2006.

SUKHIJA, P. S.; PALMQUIST, D. L. Dissociation of calcium soaps of long-chain fatty acids in rumem fluid. Journal of Dairy Science, v. 73, p. 1784-1787, 1990.

THOMAS, T.; BURGUERA, B. Is leptin the link between fat and bone mass? Journal of bone and mineral research, Amsterdam, v. 17, p. 1563-1569, 2002.

TOOMEY, S. et al. Regression of preestablished atherosclerosis in the apoe--- mouse by conjugated linoleic acid. Biochemical society transactions, London, v. 31, n. 5 , p. 1075-1079, 2003.

TRUITT, A. et al. Antiplatelet effect of conjugated linoleic acid isomers. Biochimica et biophysica acta, Amsterdam, v. 1438, n. 2, p. 239-246, 1999.

VAN NIEUWENHOVE, C. et al. Conjugated linoleic acid in buffalo (bubalus bubalis) milk from northwest Argentina. Milchwissenschaft, v. 59, n. 9-10, p. 506-508, 2004.

VÁRADYOVÁ, Z. et al. Comparison of fatty acid composition of bacterial and protozoal fractions in rumen fluid of sheep fed diet supplemented with sunflower, rapeseed and linseed oils. Animal feed science and technology, v. 144, n. 1, p. 44-54, 2008. 
WANG, S. et al. Strain field of interstitial hydrogen atom in body-centered cubic iron and its effect on hydrogen-dislocation interaction. Scripta Materialia, v. 68, n. 5, p. 249-252, 2013.

WANG, Y. M.; JONES, P. J. H. Conjugated linoleic acid and obesity control: efficacy and mechanisms. International journal of obesity, London, v. 28, n. 8, p. 941-955, 2004 .

WOOD, J. D. et al. Effects of fatty acids on meat quality: a review. Meat science, v. 66, n. 1, p. $21-32,2003$.

YAMASAKI, M. et al. Dietary conjugated linoleic acid increases immunoglobulin productivity of sprague-dawley rat spleen lymphocytes. Bioscience, biotechnology and biochemistry, Tokyo, v. 64, n. 10, p. 2159-2164, 2000.

YURAWECZ, M. P. et al. Variations in isomer distribution in commercially available conjugated linoleic acid. Fett/lipid, Leinfelden, v. 101, n. 7, p. 277-282, 1999.

ZULET, M. A. et al. Inflammation and conjugated linoleic acid: mechanisms of action and implications for human health. Journal of physiology and biochemistry, Pamplona, v. 61, n. 3, p. 483-494, 2005.

Recebido em: 10/09/2016 Aceito em: 05/11/2017 